\title{
DESAFIOS DO USUÁRIO NA INTERAÇÃO ESPAÇO VERSUS MOBILIÁRIO NAS UNIDADES HABITACIONAIS REDUZIDAS
}

\author{
RANGEL, Márcia Moreira (1); \\ INHAN MATOS, Ligia Aparecida (2) \\ (1) IF Sudeste MG - Campus Juiz de Fora, Dra. \\ e-mail: marcia.rangel@ifsudestemg.edu.br \\ (2) ) IF Sudeste MG - Campus Juiz de Fora, Dra. \\ e-mail:ligia.inhan@gmail.com
}

\begin{abstract}
RESUMO
As Habitações de Interesse Social (HIS) do Programa Minha Casa Minha Vida (PMCMV) tem sido objeto de estudo de muitos campos acadêmicos. No campo da ergonomia, este artigo objetiva avaliar o espaço e a adequação do mobiliário nas HIS. A metodologia apresenta um estudo qualitativo multimétodos em seis HIS e pesquisas no mercado local. Os resultados confirmam a inadequação dos espaços em relação ao mobiliário; o custo excessivo de mobiliário planejado ou modulado e a escassez de mobiliário adequado no mercado. Conclui demonstrando a necessidade de conhecer os usuários e suas dificuldades na interação espaço versus mobiliário.
\end{abstract}

Palavras chave: Ergonomia do ambiente construído; mobiliário; Programa Minha Casa Minha Vida.

\begin{abstract}
The program My House My Life's social housings [SH] are objects of study for several academic fields. In ergonomics, this paper intends to evaluate the space and adequacy of furniture in the SH. The methodology presents a qualitative, multi-method study of six habitation units and research in the local market. The results confirm the inadequacy of these spaces relative to the furniture; the excessive cost of planned or modular furniture and the scarcity of adequate furniture in the market. It concludes showing the necessity of knowing the users and their difficulties in the furniture versus space interaction.
\end{abstract}

Keywords: Build environment ergonomics; furniture; My House My Life Program.

\section{INTRODUÇÃO}

Políticas públicas como o Programa Minha Casa Minha Vida (PMCMV), sempre tiveram grande empenho dos governos como forma a minorar a situação das pessoas que habitam em situações de risco. Mas devido às condições mínimas de espaço de uso interno dos projetos de edificação das Habitações de Interesse Social (HIS) foi constatado, em vasta literatura sobre avaliação de políticas públicas, que os usuários estão tendo inúmeros problemas relacionados ao espaço, seja pela falta de adequação do mobiliário disponível no mercado, seja porque eles não dispõem de recursos, de conhecimento e de acesso aos profissionais. 


\section{$\ddot{1}^{\text {eneac }}$}

Dessa forma, é necessária a elaboração de ideias e inovações no campo do design contemplando a usabilidade, a acessibilidade e o conforto do mutuário da edificação. Aliado a isso, o usuário pode ser conscientizado não somente acerca das melhores possibilidades para o aproveitamento do seu espaço com a utilização do mobiliário, como também, das possibilidades para viabilizar tal uso.

Esse artigo apresenta os dados do projeto de extensão desenvolvido no IF Sudeste MG / Campus Juiz de Fora. A pesquisa teve como objetivo geral contribuir para repensar 0 mobiliário disponível no mercado brasileiro, acessível ao público de baixa renda.

As hipóteses norteadoras do trabalho versam que as HIS do PMCMV têm seu espaço reduzido, não importando para que faixa de salário, se de 0 a 3, se de 3 a 6 , ou mais; há baixa oferta de móveis específicos para esses espaços e os que estão disponíveis, não possuem design adequado para acessibilidade, seja no uso diário normal, seja para o portador de necessidades especiais; essa escassez de projetos tem relação direta com a ausência de avaliação do uso do mobiliário com as famílias em seus lares.

Essa pesquisa tem base na Ergonomia do Ambiente Construído, pois busca compreender como os usuários interagem com espaço construído e seu mobiliário nas moradias do PMCMV. As reflexões geradas a partir dos resultados participam do aporte teórico norteador para projetos cujo olhar é voltado para as necessidades reais dos usuários, sobretudo aqueles que não contam com ajuda profissional para desenvolver melhor layout e organizar o uso do mobiliário e do espaço.

\section{REFERENCIAL TEÓRICO}

O conceito de HIS está relacionado diretamente a uma estratégia de inclusão social para famílias de baixa renda (entre zero e três salários mínimos), tendo como princípio básico a moradia digna, capaz de promover inclusão, aliada aos princípios de identidade, privacidade e de convívio familiar de seus moradores (SILVA e SILVA, 2013).

Baseando nesses conceitos, o processo de construção do Plano Nacional de Habitação (PlanHab) teve intensa participação popular e dentre outras especificidades levantadas, havia a recomendação da área útil das HIS fosse de $45,82 \mathrm{~m}^{2}$ para apartamentos tipo do PMCMV (BRASIL, 2010). Além dessas especificidades, o PlanHab também abrangeu os direitos das pessoas com deficiência, sendo que até 2001 não havia requisitos para acessibilidade. Os Decretos o 5.296 de 2 de dezembro de 2004 e 7.612, de 17 de novembro de 2011 incorporaram e regulamentaram exigências legais e normativas a fim de garantir a acessibilidade física.

Mas devido à crise econômica e ao enfraquecimento do Ministério das Cidades como formulador e condutor da política urbana, a partir de 2009, o governo optou por adotar a proposta da construção civil para a produção de habitações em massa. O PlanHab foi negligenciado e os apartamentos tipo foram projetados e executados com apenas $37 \mathrm{~m}^{2}$ de área útil, conforme Cartilha da Caixa Econômica Federal (CAIXA), publicado em 2010 (AMORE, 2015; ANDRADE e DEMARTINI, 2017; KRAUSE et al, 2013).

Após as análises dos resultados e das críticas ao programa, dada a precarização da moradia, repetindo os mesmos erros de políticas anteriores (AMORE, 2015; ANDRADE e DEMARTINI, 2017; KRAUSE et al, 2013, 2013; VILLA et al, 2015)

A partir de 2016, novas especificações técnicas foram editadas pela portaria 146, de 26 de abril de 2016. Dentre as muitas alterações nas especificações técnicas, as mais significativas para esta pesquisa foi o aumento da área útil do apartamento tipo para $41 \mathrm{~m}^{2}$. Essa importante alteração foi decorrência da obrigatoriedade da HIS ter acessibilidade universal, cujas dimensões dos ambientes afetam e são afetados pelo espaço que o mobiliário ocupa (AMORE, 2015; CALADO; ELALI, 2016). 


\section{(x) $^{\text {remax }}$}

Campos e Mendonça (2013) afirmam que as áreas construídas dos apartamentos diminuíram de $100 \mathrm{~m}^{2}$ para menos de $58 \mathrm{~m}^{2}$ nos últimos 50 anos, sendo uma tendência para as unidades habitacionais de todas as classes sociais. Em contramão a essa convergência, constata-se ainda que há uma escassez de equipamentos e mobiliário na oferta da indústria moveleira para Unidades Habitacionais Reduzidas (UHR) para baixos orçamentos (CURCIO; DOS SANTOS, 2017).

Esses autores apresentam o paradoxo de um lado, pelo showroom de apartamentos decorados com móveis sob medida e de luxo, voltados para a classe A/B e por outro lado, pelas lojas comerciais que oferecem modulados com tamanhos muito mais reduzidos para 0 perfil do público do PMCMV.

Branco Pedro et al. (2011) e Boueri et al. (2012), Lopes e Shimbo (2015), Branco Pedro et al, (2012) reforçam que é impossível defender a adequação das dimensões dos cômodos pelos parâmetros mínimos definidos pela CAIXA somando-se as áreas de influência dos móveis. A pesquisa destes autores incluiu a análise das peças mobiliárias adquiridas através do Programa Minha Casa Melhor, cujo sistema de financiamento facilitava a aquisição de móveis e eletrodomésticos pelas famílias contempladas pelo PMCMV, chegando a conclusão de que torna-se impossível acomodar todo o mobiliário mínimo sem limitar a circulação e demais funções da UHR drasticamente. Ocorre uma incompatibilidade entre ambiente e móvel, fazendo que o mobiliário não favoreça a organização espacial adequada, o que acaba resultando em circulação restrita e falta de conforto (SOARES; NASCIMENTO, 2008).

As questões projetuais de arquitetura e urbanismo desenvolvido pelas construtoras e pelo design de móveis de responsabilidade do setor moveleiro não resolvem a questão do espaço útil dos imóveis (LOPES; SHIMBO, 2015; SOARES; NASCIMENTO, 2008). Se por um lado, as construtoras ao reduzir o tamanho dos imóveis, descuidaram da capacidade arquitetônica de resolver problemas de área útil, por outro lado, a indústria moveleira descuidou de aprimorar o seu design para atender a esse descuido projetual.

\section{METODOLOGIA}

Esta é uma pesquisa qualitativa, com abordagem multimétodos, desenvolvendo uma pesquisa bibliográfica e documental, estudos de caso e pesquisas exploratórias. Foram utilizadas técnicas de observações, brainstorming, entrevistas, registros fotográficos e mapeamento do espaço construído habitado.

\subsection{Pesquisa bibliográfica}

$\mathrm{Na}$ primeira fase do projeto, foi feito um levantamento das referências bibliográficas correspondentes aos fundamentos sobre mobiliário para HIS, a política pública referente e atuais debates sobre resultados da implantação do PMCMV, através do Plano Nacional de Habitação; das análises e avaliações das políticas públicas tanto de Juiz de Fora, quanto do Brasil (CARDOSO et al., 2013; UFJF - NUGEA, 2012); das pesquisas sobre acessibilidade para usuários com deficiência no PMCMV (CALADO e ELALI, 2016); da história e o desenvolvimento do mobiliário para HIS ao longo de dois séculos (FOLZ, 2012); dos métodos para produção de ideias (PAZMINO, 2015) e as necessidades de espaço útil do mobiliário (BRANCO PEDRO, 2011). Também foram aprofundados conhecimentos, captados de diversos autores, acerca da Ergonomia e da Ergonomia do produto e do ambiente construído, pertinentes às disciplinas Ergonomia I e Ergonomia II do curso de Design de móveis. 


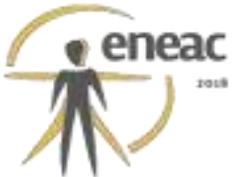

\subsection{Pesquisa documental}

Foram realizados levantamentos de projetos arquitetônicos de condomínios, com o objetivo de analisar as plantas baixas, verificar tamanhos e proposições de ocupações; definir os estudos de caso; preparar plantas baixas no software Autocad para os estudos da pesquisa.

\subsection{Estudos de caso}

Com o propósito de investigar a interação usuário $\mathrm{x}$ ambiente $\mathrm{x}$ mobiliário no espaço construído das HIS do PMCMV, foram realizados visitas a seis famílias em três condomínios em Juiz de Fora (MG) e adotou-se o Método do Estudo de Caso.

Goode \& Hatt (1979, p. 422) apontam que "o Estudo de Caso não é uma metodologia específica, mas uma forma de organizar dados preservando o caráter único do objeto social em estudo". Visa preservar e compreender o caso no seu todo e na sua unicidade. A escolha desse método é pertinente ao estudo de "eventos contemporâneos, situações onde os comportamentos relevantes não podem ser manipulados, e onde é possível se fazer observações diretas e entrevistas sistemáticas" (YIN, 2005, p. 33).

O quadro 1 apresenta as UHR que conformaram o campo de estudo da pesquisa.

\section{Quadro 1 - Descrição das UHR visitadas}

\begin{tabular}{|c|l|}
\hline UHR & \multicolumn{1}{c|}{ Descrição dos Condomínios } \\
\hline 3 unidades & $\begin{array}{l}\text { Bairro Barbosa Lage - bairro popular afastado do centro da cidade. Os imóveis têm } \\
\text { dois quartos, sala, banheiro e área de serviço conjugada à cozinha, em uma área } \\
\text { total de } 37 \mathrm{~m}^{2} \text {. } \\
\text { Condomínio fechado com } 240 \text { apartamentos distribuídos em } 12 \text { blocos de cinco } \\
\text { andares, com } 20 \text { unidades cada. Faixa de renda 1, de } 0 \text { a } 3 \text { salários mínimos }\end{array}$ \\
\hline 2 unidades & $\begin{array}{l}\text { Bairro Previdenciários - bairro popular afastado do centro da cidade. Os imóveis têm } \\
\text { dois e três quartos, sala, banheiro e área de serviço conjugada à cozinha, em uma } \\
\text { área total de } 45 \mathrm{~m}^{2} . \\
\text { Condomínio fechado com } 32 \text { apartamentos distribuídos em } 2 \text { blocos de quatro } \\
\text { andares, com } 16 \text { unidades cada. Faixa de renda 2, de } 3 \text { a } 6 \text { salários mínimos. }\end{array}$ \\
\hline 1 unidade & $\begin{array}{l}\text { Bairro Democrata - bairro melhor localizado do que os bairros apresentados } \\
\text { anteriormente. } \\
\text { Condomínio fechado com } 500 \text { apartamentos distribuídos em } 5 \text { blocos de } 10 \text { andares, } \\
\text { com } 12 \text { unidades cada. Faixa de renda 2, de } 3 \text { a } 6 \text { salários mínimos. }\end{array}$ \\
\hline
\end{tabular}

Fonte: Núcleo Design - IF Sudeste MG

Para preparar as entrevistas os bolsistas realizaram um brainstorming no qual elaboraram 28 perguntas e após essa etapa, as questões foram respondidas pelos próprios bolsistas com uma única palavra escrita em post-its. Esses post-its foram dispostos na lousa branca e a partir dessa visualização, pôde ser feita uma taxonomia com três diferentes grupos: funcionalidade/praticidade, estética e desejo. Assim, foi possível efetuar um refinamento das questões, que foram reduzidas a somente sete perguntas fechadas para traçar o perfil do usuário e 11 abertas para a entrevista. Para a categoria estética, os bolsistas pesquisaram imagens baseadas nos conceitos "estética moderna" e "universo popular", cor e não cor (mais cor e menos cor). Ao final das perguntas, os respondentes eram convidados a observarem as imagens e escolherem aquela que consideravam a mais bonita e explicar 0 porquê da escolha. 


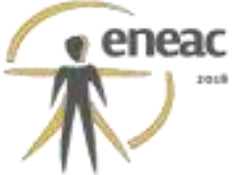

\subsection{Visitas exploratórias}

Foram realizadas três visitas exploratórias, conforme apresentado a seguir:

1. Em lojas de departamento que ofertam mobiliário para o público do PMCMV. Buscou-se levantar valores e características como tamanhos, cores, acabamentos de ambientes mobiliados;

2. Em três UHR previamente mobiliados para venda por imobiliárias em parceria com lojas de móveis planejados;

3. Em lojas de planejados modulados para UHR. O objetivo desse contato foi verificar os preços de mobiliários modulados para compor ambientes de UHR.

\section{RESULTADOS}

Os dados coletados convergiram com as hipóteses levantadas e visaram compreender como os usuários interagem com o mobiliário no espaço construído das moradias do PMCMV. Os principais resultados obtidos foram organizados e apresentados a seguir:

\subsection{Estudos de caso}

Os estudos de caso aconteceram em dois momentos distintos e com públicos diversificados. No primeiro momento, foram visitadas três famílias em um condomínio voltado para o público de baixa renda da faixa 1, do PMCMV. Os resultados foram analisados e após, foram realizados os três casos com usuários com renda da faixa 2 .

As pesquisadoras juntamente com os bolsistas observaram e fotografaram os usuários nos ambientes de sua casa, procurando deixá-los ao máximo à vontade e bem receptivo. As entrevistas iniciaram nesse clima de informalidade buscando captar também questões ocorridas no momento.

O quadro 2, a seguir, descreve o perfil de todos os usuários entrevistados, segundo as categorias de sexo, idade, escolaridade, faixa de renda e número de residentes.

Quadro 2 - Perfil dos usuários

\begin{tabular}{|c|c|c|c|c|c|c|c|}
\hline \multicolumn{8}{|c|}{ PERFIL DO USUARIO } \\
\hline \multirow{2}{*}{\multicolumn{2}{|c|}{ CATEGORIAS }} & \multicolumn{6}{|c|}{ USUARIOS } \\
\hline & & 1 & 2 & 4 & 5 & 6 & 7 \\
\hline \multicolumn{2}{|c|}{ Sexo } & $\mathrm{F}$ & $\mathrm{F}$ & $\mathrm{F}$ & $\mathrm{F}$ & $\mathrm{F}$ & $\mathrm{F}$ \\
\hline \multicolumn{2}{|c|}{ Idade } & 60 a 64 & 20 a 24 & 50 a 54 & +70 & 50 a 54 & 30 a 34 \\
\hline \multicolumn{2}{|c|}{ Escolaridade } & $\mathrm{FII} / \mathrm{C}$ & Fll/in & Fll/in & $\mathrm{Fl} / \mathrm{C}$ & $\mathrm{FII} / \mathrm{c}$ & $\mathrm{PG} / \mathrm{C}$ \\
\hline \multirow{3}{*}{$\begin{array}{l}\text { Faixa de } \\
\text { renda }\end{array}$} & $\begin{array}{c}\text { Bolsa } \\
\text { família }\end{array}$ & 1 a 3 & 1 a 3 & - & - & - & - \\
\hline & LOAS & - & - & Sim & - & - & - \\
\hline & $\begin{array}{l}\text { Faixa de } \\
\text { sal.mínimo }\end{array}$ & Até 2 & Até 2 & Até 2 & de 3 a 6 & de 4 a 10 & de 4 a 10 \\
\hline \multirow{2}{*}{$\begin{array}{c}\mathrm{N}^{\circ} \\
\text { residentes }\end{array}$} & Adulto & 1 & 2 & 3 & 2 & 3 & 1 \\
\hline & Criança & 3 & 5 & 0 & 0 & 0 & 0 \\
\hline
\end{tabular}

Legenda: Fundamental I completo/incompleto (FIc/in); Fundamental II completo/incompleto (FIIc/in); Ensino Médio completo/incompleto (EM c/in); Graduação completo/incompleto (Gc/in); Pós-graduação completo/incompleto (PGc/in). LOAS (lei Orgânica de Assistência Social).

Fonte: Núcleo Design - IF Sudeste MG

Os quadros 3 e 4 mostram a planta baixa dos apartamentos visitados e algumas informações e imagens coletadas. 


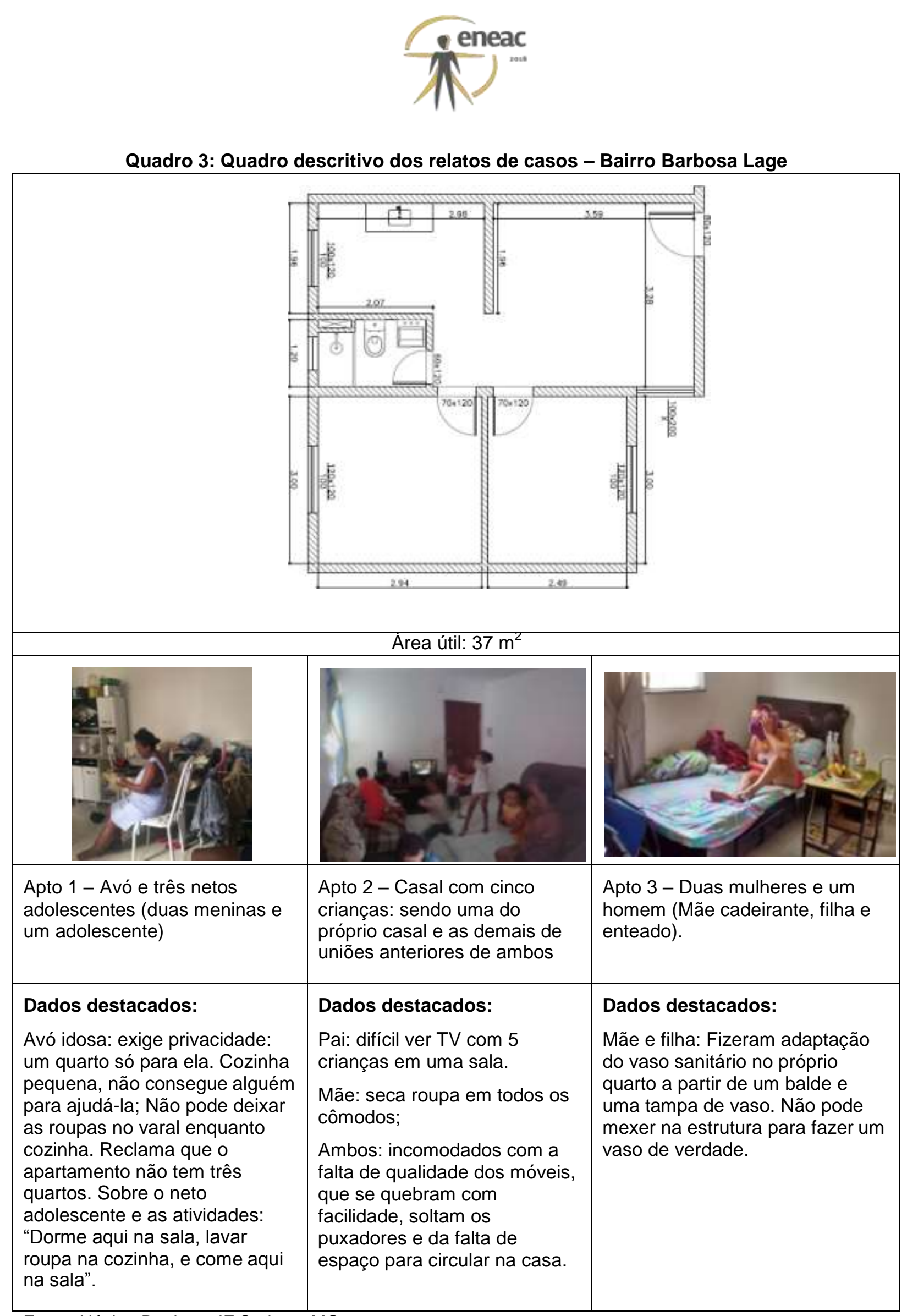

Fonte: Núcleo Design - IF Sudeste MG 


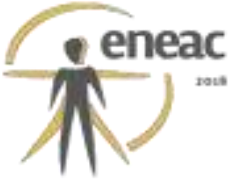

Quadro 4: Quadro descritivo dos relatos de caso Bairros Previdenciários e Democrata

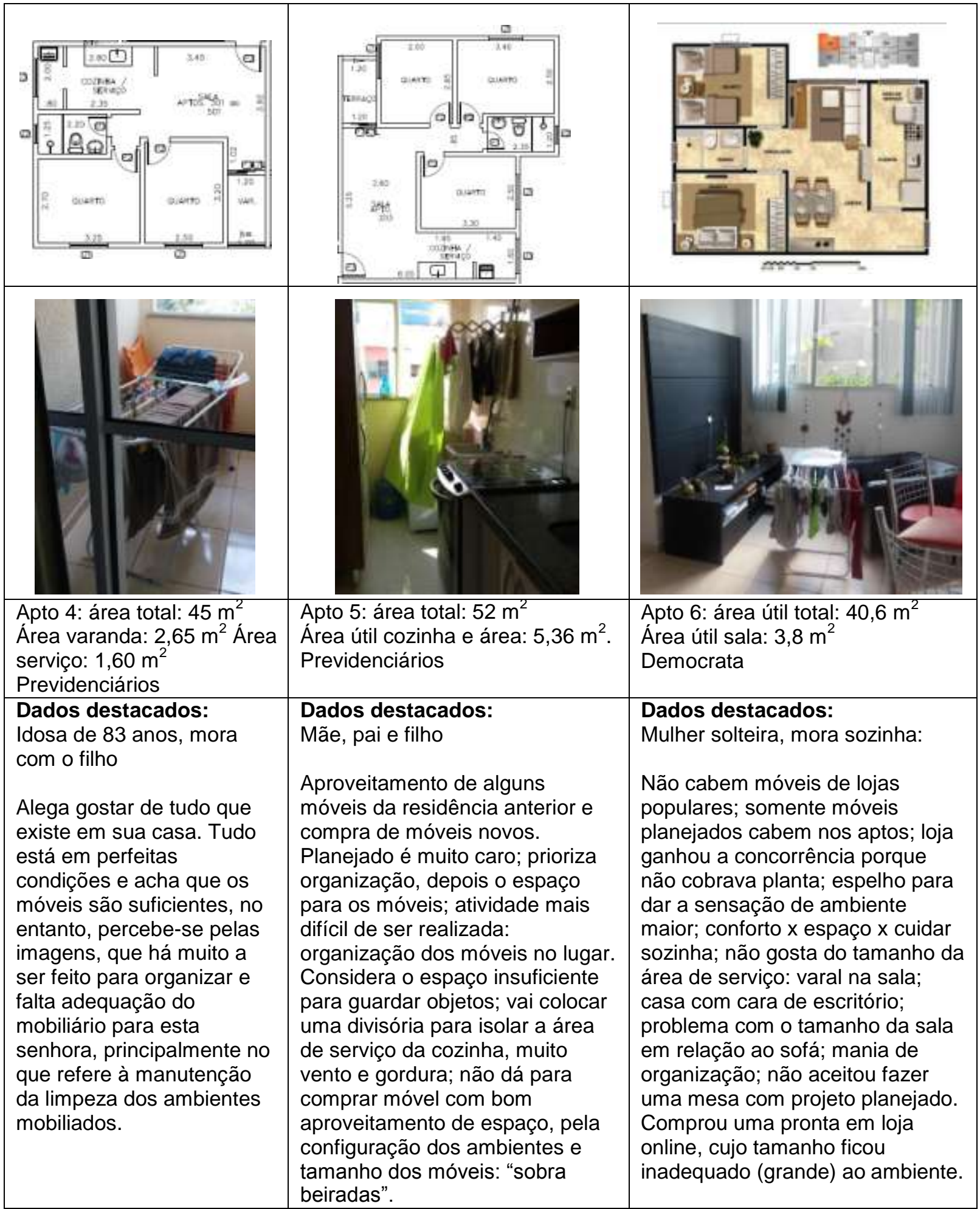

Fonte: Núcleo Design - IF Sudeste MG

Observou-se que na questão da estética, os respondentes das três famílias da faixa 1, não justificaram suas escolhas pelo fator estético, mas pelo funcional das imagens dos móveis apresentados. Dessa forma, o que era bonito vinha acompanhado de frases como "parece durável"; "dá para guardar bastante coisa"; "olha Daiane, dá para guardar livros, roupas".

No mapeamento dos ambientes dos casos, foram alocados o mobiliário existente nas plantas baixas e realizados estudos de fluxos e de circulação. Depois, foram realizados 


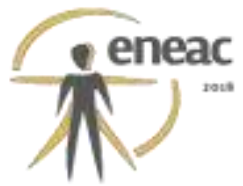

novos estudos de layout para verificar se haveria melhor disposição dos móveis. Os resultados mostraram que não há muitas possibilidades de variação; há pouco ganho de espaço e possibilidades de armazenamento dos objetos e roupas.

Em todos os estudos de caso, seja para famílias numerosas ou mesmo para o apartamento com uma única pessoa, a área de serviço (ou falta dela) é o cômodo com maior problema de espaço e influenciador na desorganização da casa.

\subsection{Visitas exploratórias}

\subsubsection{Visitas ao mercado local}

Foram realizadas visitas nas lojas Magazine Luiza; Casas Bahia e Ricardo Eletro onde há móveis para o público do PMCMV. Também foi feita uma visita em uma loja Parma, cujo público é da classe média alta, a fim de sondar as possibilidades de móveis seriados para UHR. Verificou-se que nas lojas de departamento, o mobiliário ora é grande demais para o espaço, ora é reduzido. A medida reduzida aponta para a economia de material para privilegiar o preço. Quanto às opções de mobiliário com flexibilidade de uso, maior aproveitamento dos espaços internos e multifuncionais, encontrou-se somente sofás articulados que se tornam camas, o restante do mobiliário é tradicional. Na loja Parma, há mais possibilidade de móveis menores e avulsos e móveis planejados.

\subsubsection{UHR mobiliadas para venda de apartamentos}

Das UHR visitadas, somente uma delas, localizada na Av. 7 de Setembro, se encaixava na faixa de renda do PMCMV, com área útil de $45 \mathrm{~m}^{2}$, cujo valor do imóvel é até $R \$ 190 \mathrm{mil}$. As duas outras UHR estão localizadas no bairro São Mateus e no bairro Mariano Procópio e possuem área útil de $54,57 \mathrm{~m}^{2}$ e $52 \mathrm{~m}^{2}$, respectivamente. Cabe observar que os valores das UHR estão vinculados ao valor de mercado da localização, do que às suas diferenças de metragem e planta. A figura 1 demonstra as plantas baixas humanizadas e o valor da UHR.

Figura 1 - Plantas baixas humanizadas das UHR visitadas, sala decorada e valores de venda.

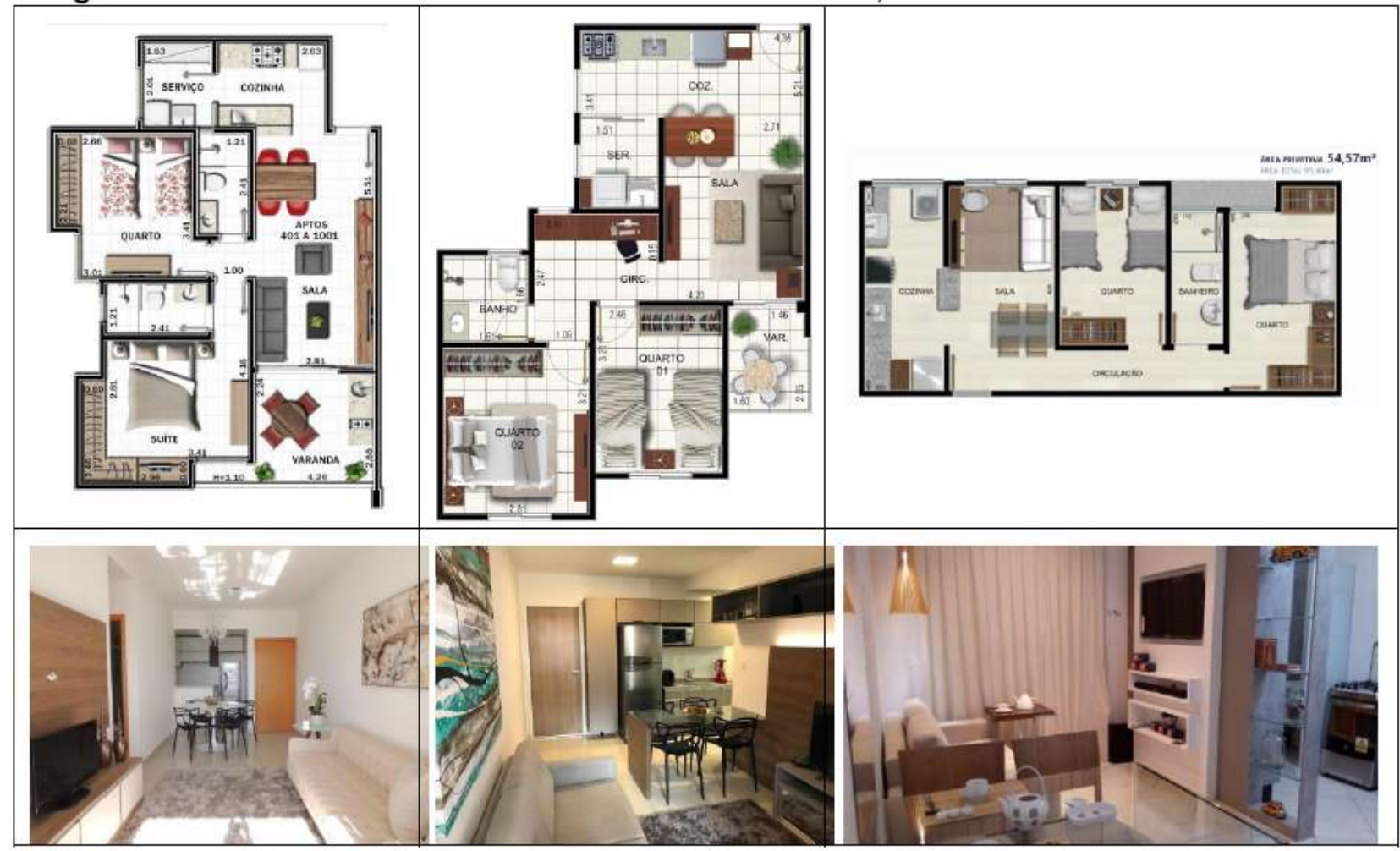




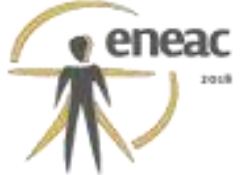

\begin{tabular}{|l|l|l|}
\hline $\begin{array}{l}\text { R. Dr. Duarte de Abreu, } \\
114, \\
\text { Procópio }\end{array}$ & $\begin{array}{l}\text { Av. } 7 \text { de Setembro, Bairro } \\
\text { Costa Carvalho }\end{array}$ & R. Guaçuí, 300, Bairro São Mateus \\
\hline Valor: $\mathbf{R} \mathbf{3 2 7 . 9 0 0 , 0 0}$ & Valor: $\mathbf{1 9 0 . 0 0 0 , 0 0}$ & Valor: $\mathbf{R} \mathbf{2} \mathbf{2 3 8 . 9 0 0 , 0 0}$ \\
\hline
\end{tabular}

Fonte: Souza Gomes Imóveis, 2017.

De fato, esses modelos não existem na realidade: dois foram montados no stand de vendas no local da construção da futura edificação e o do Bairro São Mateus foi montado dentro da própria loja de móveis que executou o projeto de mobiliário.

\section{DISCUSSÃO}

Tanto as visitas técnicas nas UHR mobiliadas, quanto as visitas nas UHR do PMCMV, corroboraram as hipóteses norteadoras dessa pesquisa e apresentadas na introdução do artigo.

Quando há móveis planejados especificamente para o espaço, o conforto é melhor, mas se os móveis são de lojas de departamento, há problemas de arranjo.

Foi possível constatar que as UHR com móveis planejados previamente instalados pelas imobiliárias têm servido como um modelo, com a finalidade de aumentar o desejo da compra pelo consumidor. Por outro lado, também prova que é possível adequar melhor o mobiliário mesmo em pequenos espaços.

A escala real, com todo o aparato decorativo, tem sido utilizada em muitos lançamentos de venda de imóveis na planta baixa. Essa nova rotina no processo da venda demonstra que essa estratégia de vendas é importante. É o arranjo ideal de móveis no espaço útil, primando pela aparente qualidade e até mesmo com algum luxo. Porém, como é um projeto idealizado, não há a preocupação de custo para este tipo de arranjo.

Dessa forma, após ter acesso aos orçamentos as lojas de planejados responsáveis pelo projeto mobiliário, foram constatados que os preços do projeto podem chegar a quase metade do valor do imóvel na planta baixa, sem os elementos decorativos, colchões, utensílios domésticos, etc. A Figura 3 apresenta os valores de planejados para um cômodo.

\section{Figura 3 - Quartos montados para demonstração para vendas*.}

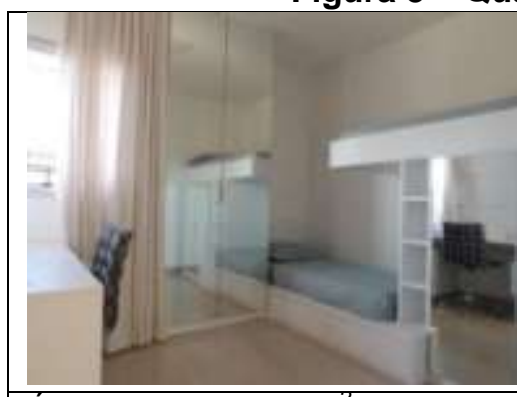

Área útil quarto: $9 \mathrm{~m}^{2}$

R. Dr. Duarte de Abreu, 114,

Bairro Mariano Procópio

Valor do planejado:

$\mathbf{R} \$ 32.000,00$ (sem desconto)

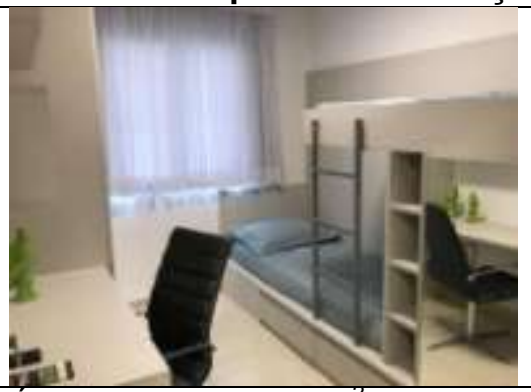

Area útil quarto: $7,8 \mathrm{~m}^{2}$.

Av. 7 de Setembro, Bairro Costa Carvalho

Valor do planejado:

R\$23.369,00 (sem desconto)

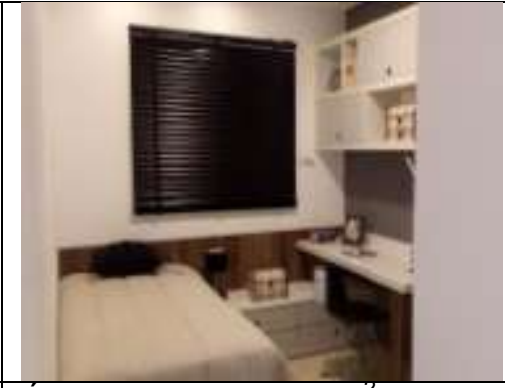

Área útil quarto: $8,6 \mathrm{~m}^{2}$

R. Guaçuí, 300, Bairro São

Mateus

Valor do planejado:

$\mathbf{R} \$ 14.750,00$ (sem desconto)

*Note que a decoração quase se repete no quarto dos Bairros Mariano Procópio e Costa Carvalho.

Fonte: Núcleo Design - IF Sudeste MG

Essas descobertas ressaltaram a discrepância dos valores dos imóveis versus mobiliário, assim como a necessidade atual do usuário adquirir móveis planejados a fim de obter melhor conforto e aproveitamento nessas HUR, já que não há móvel adequado no mercado. 


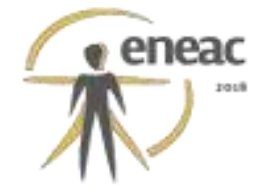

A problemática relacionada à acessibilidade universal foi constatada em duas UHR, pois tanto a idosa quanto a cadeirante apresentam problemas de adaptação ao espaço, seja na limpeza do ambiente, como é o primeiro caso, ou na dificuldade de locomoção, no segundo caso.

O espelho tem sido utilizado amplamente pelos decoradores para "dar a impressão" de maior espaço. Com esse mesmo intuito, a usuária de melhor poder aquisitivo colocou um grande espelho em sua sala de jantar.

No caso das UHR com até três moradores da faixa 2 do PMCMV, também foi constatado nas entrevistas, que embora as usuárias concordem que o espaço é reduzido, os quartos e o banheiro foram apontados como sendo adequados. Já a cozinha e a sala variaram de adequação conforme a usuária. Duas moradoras utilizam o quarto extra para tarefas diferentes da de dormir, como sala de jantar, escritório e/ou closet.

Todas as usuárias reclamaram da área de serviço. Ela não é dimensionada suficientemente para completar a tarefa de lavar-secar roupas no mesmo lugar, pois não há espaço para varais e nem é adequadamente isolada da cozinha. $O$ vão de iluminação e a ventilação são compartilhados com os dois ambientes, dificultando, ou mesmo impossibilitando, a realização e a separação das tarefas. Foi observado que varais de pé ficam dispostos fora do ambiente apropriado, como sala ou varanda, quando esta existe. Nas duas UHR onde haviam mais de quatro moradores, foi observado varais e roupas espalhadas em todos os ambientes.

As observações demonstraram que as plantas dos imóveis não são amigáveis com móveis padronizados e isso foi confirmado pelos usuários UHR visitadas.

Constatou-se que os apartamentos visitados com mais de três moradores, não são adequados às famílias, pois no caso de filhos de gêneros diferentes haverá o problema da divisão do quarto quando atingirem a adolescência. Esse problema foi levantado pelos moradores que têm crianças em casa.

A realidade brasileira se compõe de uma configuração familiar heterogênica também foi percebida nas pesquisas de Branco Pedro et al (2011), Boueri et al (2012) e Branco Pedro et al (2012). Nos estudos de caso aqui apresentados, verifica-se a falta de conhecimento e o descaso para conhecer, ouvir e levar em conta o usuário e seus modos de vida. Tal situação tem levado a conflitos entre os usuários e seus "novos" espaços. Isso é visível e foi relatado em tom de tristeza e ainda com um pedido de ajuda da senhora que vive com os netos. Para ela, diante do espaço exíguo e sem possibilidades de "receber toda a família", o sonho da casa própria virou pesadelo.

\section{CONCLUSÕES}

As experiências obtidas neste projeto puderam ressaltar que o problema do mobiliário para UHR perpassa, necessariamente pelos seguintes pontos:

1) A partir da observação do mercado local, o setor moveleiro não atende a necessidade de móveis multifuncionais para a classe média, como também não atende à classe baixa no aspecto qualitativo e dimensional dos móveis;

2) Embora os achados encontrados convirjam para os resultados de avaliações do PMCMV pelo Observatório das Metrópoles (AMORE et al, 2015) e pelo projeto [MORA] Pesquisa em Habitação (VILLA et al, 2015), o padrão dimensional reduzido dos imóveis da atualidade atinge a uma ampla faixa da população. Esse projeto revelou que mesmo que se os usuários consigam mobiliar sua UHR com móveis planejados ou modulados, o preço pago é desproporcional ao valor do imóvel, em alguns casos chegando a metade do seu valor, dificultando a adequação do espaço ao usuário; 


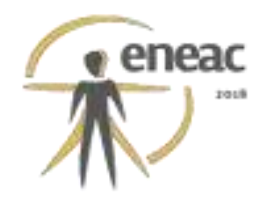

3) Problema de projeto arquitetônico: a área de serviço não é adequada ao seu propósito. O brasileiro não tem o hábito de utilizar máquina de secar, preferindo deixar a roupa secar em varais, devido ao clima propício do país. Como esse espaço não comporta totalmente a ação, o mobiliário também não consegue atender a essa necessidade. $A$ alteração de projeto pelas construtoras deveria ser obrigatória e urgente, porque: 1) uma possível, mas improvável mudança de hábito não faz sentido econômico, com aumento do gasto com energia se o usuário adquirir uma máquina de lavar e secar ou comprar uma secadora e 2) o aumento do consumo de energia exigiria uma mudança de cultura desnecessária e incoerente com os paradigmas da sustentabilidade. Além disso, a área útil desse cômodo não comporta duas máquinas. Diferente dos países de climas frios de onde foi transplantada a ideologia desse projeto, a natureza brasileira auxilia no processo de secagem de roupas e essa rotina faz parte da cultura brasileira.

Esta pesquisa gerou material teórico e ideias iniciais de layouts e de mobiliários multifuncionais. Além disso, contemplou uma moradora com um projeto de planejados para um quarto com diversos usos. Nova edição da pesquisa irá prosseguir com esse desenvolvimento de projetos, buscando o aporte das indústrias, para verificar sua viabilidade técnica e construtiva, de maneira que possam atender ao público do PMCMV.

A continuidade da pesquisa visa chegar ao desenvolvimento de políticas públicas para incorporar o mobiliário adequado ao PMCMV.

\section{REFERÊNCIAS}

AMORE, C.S.; SHIMBO, L.Z.; RUFINO, M.B.C. (Org.). Minha casa... e a cidade? Avaliação do programa minha casa minha vida em seis estados brasileiros. IPPUR/UFRJ. Rio de Janeiro: Letra Capital, 2015, 428 p.

AMORE, C.S.; Minha casa Minha vida para iniciantes. In AMORE, C.S.; SHIMBO, L.Z.; RUFINO , M.B.C. (Orgs.). Minha casa... e a cidade? Avaliação do programa minha casa minha vida em seis estados brasileiros. Rio de Janeiro: Letra Capital, 2015, p. 11-28.

ANDRADE, L.S.; DEMARTINI, J. Repensando a Prática Arquitetônica no Contexto da Moradia Social. In CARDOSO, A.L.; ARAGÃO, T.A.; JAENISCH, S.T. (orgs). Vinte e dois anos de política habitacional no Brasil: da euforia à crise. Rio de Janeiro: Letra Capital: Observatório das Metrópoles, 2017, p. 285-305.

BOUERI, J.; BRANCO PEDRO, J.; SCOARIS, R. Análise das exigências de área aplicáveis às habitações do programa Minha Casa Minha Vida. Cadernos Edifícios, CAD 7, 36. Lisboa: LNEC, 2012. p. 53-88.

BRANCO PEDRO, J. ; VASCONCELOS, L ; MONTEIRO, M ; JERÓNIMO, C. Dimensões do mobiliário e do equipamento na habitação. Lisboa: Lenec, 2011.

BRANCO PEDRO, J.; BOUERI FILHO, J.J. Exigências de espaço aplicáveis à construção de habitação de interesse social: comparação entre Portugal e o município de São Paulo. Pós - Revista do Programa de Pós-Graduação em Arquitetura e Urbanismo da FAUUSP, v. 19, n. 32, p. 116135, 2012.

BRASIL. Decreto no 5.296 de 2 de dezembro de 2004, Institui Regulamenta as Leis nos 10.048, 2004.

BRASIL. Decreto no 7.612, de 17 de novembro de 2011, Institui o Plano nacional dos direitos da pessoa com deficiência-plano viver sem limite. 2011. 


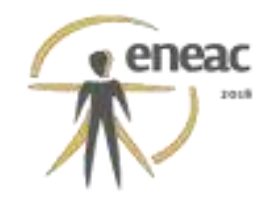

BRASIL. MINISTÉRIO DAS CIDADES. Cap. I - O que é o PlanHab. In: Plano Nacional de Habitação. Versão para debates Brasília: Ministério das Cidades/ Secretaria Nacional de Habitação. Primeira impressão: maio de 2010, 212 p.

CAIXA. Caixa Econômica Federal. Cartilha Minha casa Minha Vida. CEF e Governo Federal, 2010.

CALADO, G.C.; ELALI, G.A. Acessibilidade em Habitação de Interesse Social: estudo de caso no Residencial Waldemar Rolim. In: ENEAC Ano 10. Anais... Recife, 2016. p. 41-52.

CAMPOS, P.R.; MENDONÇA, J.G. Estrutura sócio espacial e produção habitacional na Região Metropolitana de Belo Horizonte: novas tendências. In: CARDOSO, A. L. (ORG.). O Programa Minha Casa Minha Vida e seus Efeitos Territoriais. Rio de Janeiro: Letra Capital, 2013. p. 67-92.

CARDOSO, A.L. et al. Quando um direito vira produto: impactos do PMCMV na cidade do Rio de Janeiro. Anais... XIII Simpósio Nacional de Geografia Urbana. UERJ, 2013.

CURCIO, G.O.F. DOS SANTOS, M.C.L. Móvel popular: design para a nova classe média. Pós Revista do Programa de Pós-Graduação em Arquitetura e Urbanismo da FAUUSP, v. 24, n. 42, p. 74-87, 2017.

FOLZ, R.R. Mobiliário na Habitação popular. Trabalho de dissertação. Escola de Engenharia de São Carlos da Universidade de São Paulo. São Carlos, 2002.

GOODE, W.J., HATT, P.K. Métodos em pesquisa social. 5ª. ed. São Paulo: Companhia Editora Nacional, 1979. 422 pgs.

KRAUSE, C.; BALBIM, R.; NETO, V.C.L. Minha Casa Minha Vida, nosso crescimento: Onde fica política habitacional?. Texto para Discussão, Instituto de Pesquisa Econômica Aplicada (IPEA), 2013.

LOPES, J.M.A.; SHIMBO, L.Z. Projeto e produção da habitação na região central do estado de São Paulo: condições e contradições do PMCMV. In: Minha casa... e a cidade? avaliação do programa minha casa minha vida em seis estados brasileiros. AMORE, C.S.; SHIMBO, L.Z.; RUFINO , M.B.C. (Org.). Rio de Janeiro: Letra Capital, 2015. p. 229-254.

PAZMINO, A.V. Como se cria: $\mathbf{4 0}$ métodos para o design de produtos. São Paulo: Ed. Blucher, 2015.

SILVA, B.F.; SILVA, R.D. As novas formas de provisão de moradia e seus impactos na reconfiguração socioespacial do aglomerado Sarandi-Maringá entre 2009 e 2011. In: CARDOSO, A.L. (ed.) O programa Minha Casa Minha Vida e seus efeitos territoriais. Rio de Janeiro: Letra Capital, 2013, p. 279-300.

SOARES, M.A.T. e NASCIMENTO, M.B. Moradia e mobiliário popular: problema antigo solução (im) possível? Da Vinci, Curitiba, v. 5, n. 1, p. 69-96, 2008.

UFJF - NUGEA. Relatório PMCMV. 2012. Disponível em: $<$ http://www.ufjf.br/nugea/files/2012/10/Programa-Minha-Casa-Minha-Vida.pdf $>$. Acesso em $16 \mathrm{mar}$ 2017.

VILLA, S.B.; SARAMAGO, R.C.P.; GARCIA, L.C. Avaliação pós ocupação no Programa Minha Casa Minha Vida: uma experiência metodológica. Uberlândia: UFU/PROEX, 2015.

YIN, R.K. Estudo de caso: planejamento e métodos. São Paulo: Bookman, 2001 